\title{
Ensino de engenharia a distância
}

ALEXANDRE L. VASCONCELLOS - Engenheiro de Produção, MSC, MBA

Fundador da Plataforma Digital Engeduca

\section{INTRODUÇÃO}

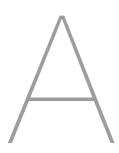

modalidade de educação a distância (EaD) não é nova. Ela tem mais de duzentos anos de existência, se for considerado o conceito original: de aprendizagem aberta, sem contato presencial regular entre professores e alunos. Entretanto, ela torna-se mais atual e difundida a cada dia em função da utilização de novas tecnologias de informação e comunicação (TIC).

No Brasil, a EaD teve sua realização legalizada a partir da Lei de Diretrizes e Bases da Educação - Lei 9.394, de 20 de dezembro de 1996 (MEC, 2020-2). A nova legislação e o crescimento da oferta de cursos a distância difundiram a modalidade, tornando o processo educacional mais inclusivo, apesar do preconceito existente.

Com base em dados do Censo da Educação Superior, em 2008 as matrículas em cursos EaD representavam $20 \%$ do total. No ano passado, superaram 40\%, com mais de 1,4 milhão de alunos e a tendência é que, em 2023, haja mais alunos matriculados na EaD do que na educação presencial (ABMES, 2020).

Essa modalidade também mostra a sua relevância na atual circunstância do ensino convencional no Brasil, quando se considera a Portaria 2.117/2019 publicada no DOU em
11/12/2019, permitindo às Instituições de Ensino Superior (IES) oferecerem até $20 \%$ de aulas a distância nos cursos presenciais, podendo chegar a $40 \%$ se a instituição privada atender a quatro requisitos, dentre eles, ter 0 curso bem conceituado (notas 4 ou 5) em avaliações do MEC. As universidades federais já estão autorizadas a oferecerem, em seus cursos presenciais, $40 \%$ das aulas a distância.

Há 487 cursos de engenharia na modalidade EaD credenciados e em atividade no Brasil. De Engenharia Civil são 101 cursos com o total de 167.694 vagas autorizadas.

A EaD veio para ficar e não mais deve-se discutir a modalidade de ensino/aprendizagem, mas o modelo que se quer adotar para ela no ensino da Engenharia.

Nesse artigo, não se pretende fazer uma abordagem teórica e/ou metodológica, mas apresentar para discussão os objetivos da EaD, as tecnologias e recursos atuais e o potencial futuro, baseados na experiência do autor, além de desmistificar os motivos que levam ao preconceito contra esta modalidade no ensino da Engenharia no Brasil.

\section{BREVE HISTÓRICO}

O estudo por correspondência foi a primeira forma importante de educação a distância, de certa forma lenta, pois a comunicação dependia da velocidade do serviço postal e do tempo de resposta entre transmissor e receptor de conteúdo.

No final de 1800, na Universidade de Chicago, foi estabelecido o primeiro grande programa de cursos particulares por correspondência dos Estados Unidos, no qual o professor e o aluno estavam em locais diferentes, caracterizando a EaD (AECT, 2020).

Em 1858, a London University se torna a primeira universidade a oferecer graduação de educação a distância (E-LEARNING INDUSTRY, 2020).

Em 1906, a Wisconsin-Madson University passa a enviar os materiais de estudo gravados para serem utilizados nos fonógrafos da época.

$\mathrm{Na}$ primeira metade do século $\mathrm{XX}$, tecnologias de transmissão, como rádio e televisão, tornaram-se essenciais em todas as casas, e as faculdades experimentaram oferecer palestras via rádio como forma de complementar os cursos por correspondência. O advento da televisão trouxe os primeiros telecursos.

Em 1969 o primeiro ministro do Reino Unido, Harold Wilson, inaugura a Open University, a primeira IES a entregar apenas conteúdo a distância, à época utilizando o rádio e a televisão (Open University, 2020), seguido pela Athabasca University (Universidade 
Aberta do Canadá), em 1970, e a Fern Universität in Hagen (Universidade Aberta da Alemanha), em 1974.

O material impresso foi substituído pelos CD-ROMs, pois, além de conter arquivos de áudio e vídeo, podiam conter dados, eram duráveis, fáceis de reproduzir e baratos de enviar por correspondência.

Os cursos com transmissão via satélite tiveram sua vez, mas necessitavam de equipamentos especiais, além de exigir o deslocamento dos alunos para uma biblioteca, polo ou outro centro de aprendizado local para acesso.

Os avanços mais recentes em tecnologias se concentraram nos computadores e na Internet. A popularidade dessas tecnologias cresceu à medida que um número crescente de computadores pessoais entrava em residências e uma quantidade crescente de dados podia ser transmitida por linhas telefônicas regulares.

A transformação trazida pela World Wide Web permitiu, em 1995, a primeira entrega de um curso a distância promovido pela Penn State University, dos Estados Unidos.

A Internet criou um boom no aprendizado on-line no final do século XX. A escolha de opções de comunicação síncrona ou assíncrona, a capacidade de adicionar áudio, vídeo, texto, enfim, arquivos multimídia, aceleraram a adesão a esta modalidade de ensino.

No Brasil, os cursos a distância em IES iniciaram no final do século $X X$. Segundo o Censo da Educação Superior 2018 (INEP, 2020), o Brasil tinha 3.177 cursos de graduação a distância, sendo 248 deles relacionados à Engenharia, Produção e Construção, 239 em instituições privadas e 9 em

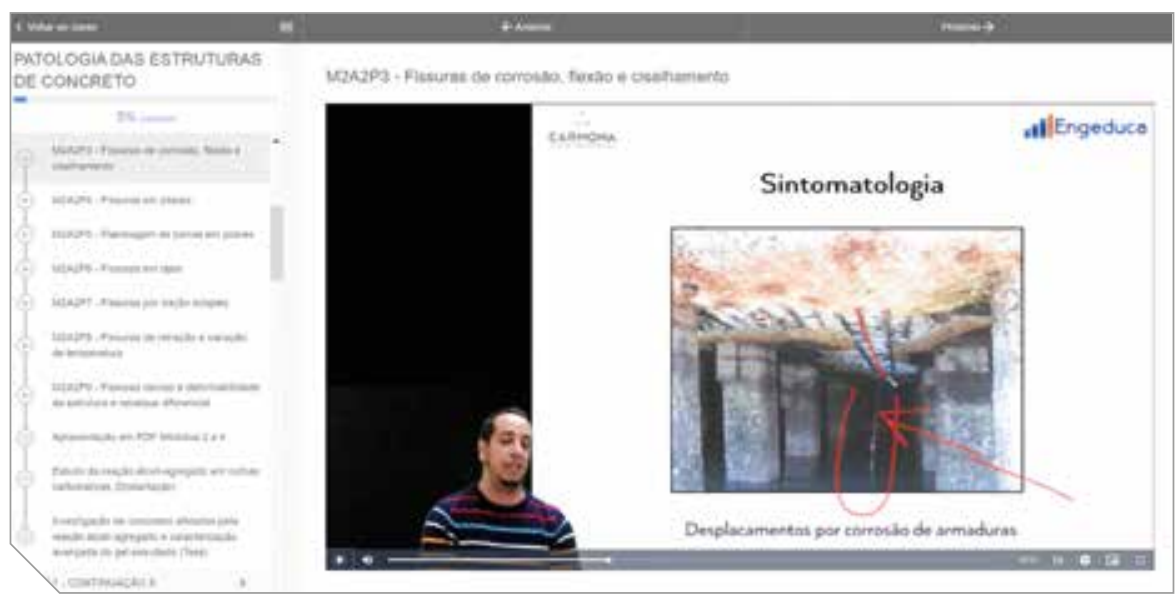

Exemplo do Ambiente Virtual de Aprendizagem (AVA). À esquerda apresenta-se a trilha de aprendizagem $\in$ o conteúdo do curso Patologia das Estruturas de Concreto na plataforma Engeduca

instituições públicas. Desses, 44 são cursos de bacharelado em Engenharia Civil, todos em instituições privadas.

Cursos de pós-graduação lato sensu, cursos de capacitação e atualização profissional e cursos livres também cresceram de forma acelerada no mundo inteiro.

Do inglês Massive Open Online Course, os MOOCs mudaram dramaticamente a maneira como o mundo aprende e impulsionou a EaD, permitindo que o estudante passasse a ter acesso a cursos das melhores universidades do mundo.

MOOCs são cursos on-line gratuitos disponíveis para qualquer pessoa se inscrever. Oferecem uma maneira acessível e flexível de aprender novas habilidades, avançar em sua carreira e oferecer experiências educacionais de qualidade em grande escala. Milhões de pessoas em todo o mundo usam MOOCs para aprender por várias razões, incluindo: desenvolvimento de carreira, mudança de carreira, preparativos para a faculdade, aprendizado suplementar, aprendizado ao longo da vida, treinamento corporativos e muito mais.
São exemplos de MOOC as plataformas: Coursera - 13 milhões de usuários (cousera.org), EDx - 4 miIhões de usuários (edx.org) e Miríada $X$ - 1,4 milhão de usuários (miríada. net). No Brasil, há a Veduca - 830 mil usuários (veduca.com.br) e, específica para a engenharia civil, a Engeduca (cursos.engeduca.com.br) 15 mil usuários.

\section{OBJETIVOS ATUAIS DA EAD NO ENSINO DA ENGENHARIA}

De acordo com o MEC (2020-1) e segundo o Decreto 5.622, de 19.12.2005, a educação a distância "é a modalidade educacional na qual a mediação didático-pedagógica nos processos de ensino e aprendizagem ocorre com a utilização de meios e tecnologias de informação e comunicação, com estudantes e professores desenvolvendo atividades educativas em lugares ou tempos diversos".

Os alunos podem morar em áreas afastadas. Nas grandes cidades, o trânsito e as grandes distâncias podem ser superados. Cada vez mais, os cursos a distância permitem que os alunos participem no local e no horário mais adequado às suas necessidades. 
Pessoas aprendem de maneiras diferentes, podem superar as barreiras dos estilos de aprendizagem e seguir os materiais instrucionais em seu próprio ritmo. Bem utilizadas e bem planejadas, as ferramentas eletrônicas de educação permitem uma experiência superior ao aprendizado tradicional, usando metodologias ativas com o auxílio de vídeo, áudio e simulações.

Destaca-se os principais objetivos da EaD no ensino da engenharia:

$>$ Proporcionar uma alternativa eficaz para oportunidades mais amplas no ensino da engenharia;

> Oferecer educação eficiente e mais barata;

> Fornecer educação a pessoas qualificadas, independente de classe social;

> Proporcionar oportunidades para melhorar o padrão de conhecimento e aprendizado por meio da educação continuada;

Fornecer aprendizado às pessoas que consideram a educação uma atividade ao longo da vida ou pretendem adquirir conhecimento em outras áreas.
A EaD ampliou seu espaço e não tem mais volta, apesar de ainda existir preconceito contra essa modalidade de ensino, gerando conflitos, não de gerações, mas de diferentes visões em relação à qualidade e possibilidades na formação profissional.

\section{O PRECONCEITO NA EAD PARA A ENGENHARIA}

Pesquisa desenvolvida por Corrêa et al. (2009) identificou "uma atitude geral de preconceito contra a EaD dentro do ambiente acadêmico estudado, apresentada principalmente sob um ceticismo quanto à qualidade dos cursos na formação do estudante, sentimento justificado pela percepção de uma falta de formação específica dos educadores para a atuação na modalidade e pela má utilização dos recursos de informática disponíveis".

Sem dúvida, há problemas de qualidade na EaD da engenharia, pois ainda existe falta de formação específica de alguns educadores para a atuação na modalidade e a má utilização dos recursos de TIC disponíveis. Mas esses pontos não podem ser genera-

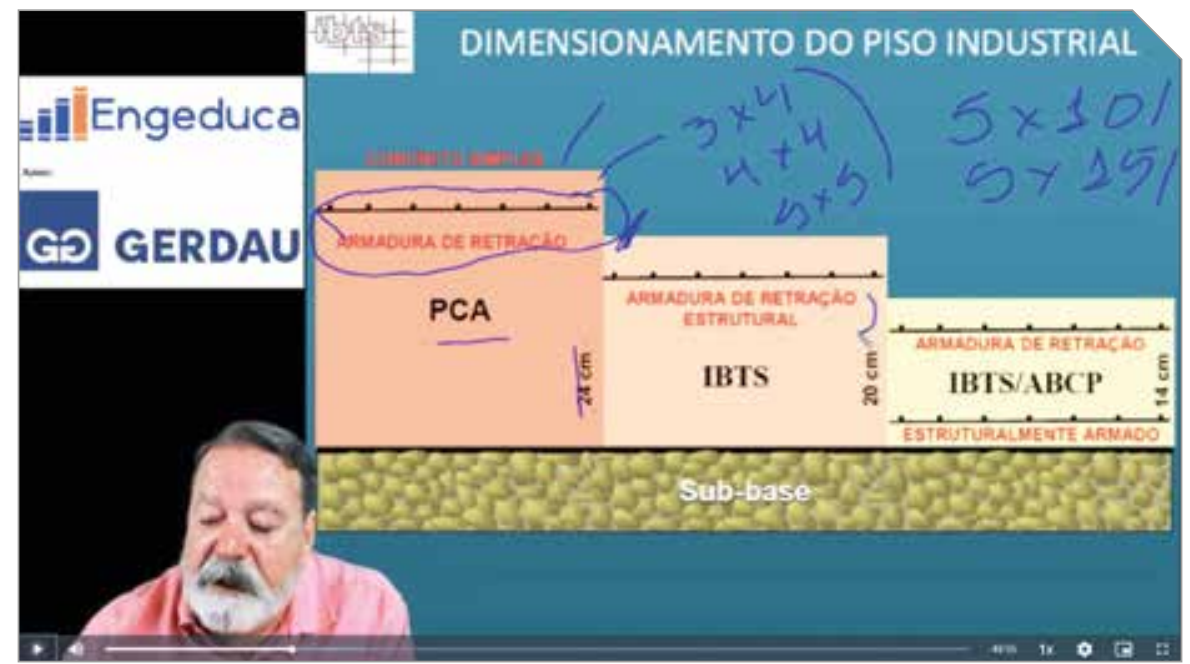

Comunicação síncrona na qual o professor utiliza com os alunos o recurso da lousa digital lizados, apesar de muitos professores que trabalham com educação a distância não estarem prontos para lidar com essa modalidade ou não querem estar.

Apesar do preconceito existente contra a EaD, dentro e fora do ambiente acadêmico, a forma de aprender mudou e a forma de ensinar tem de mudar.

Outra explicação é resultado de muitas iniciativas malsucedidas que marcaram o início da EaD no Brasil.

Em depoimento à ABMES (2020), o recrutador André Ferragut, da consultoria Hays, afirmou: "Para alguns segmentos ainda há algumas ressalvas, ainda há uma pequena dose de desconfiança em relação aos cursos a distância, mas essa dose de desconfiança tem muito mais a ver com desconhecimento sobre o quanto que o curso a distância exige também do aluno, do que especificamente uma desconfiança geral".

Tendo em vista os requisitos práticos e de habilidades da educação e treinamento de engenheiros, à primeira vista, para quem está de fora, a engenharia pode ser percebida como não ideal para ser ensinada a distância. De fato, como resultado, algumas instituições evitam desenvolver materiais de cursos de engenharia em favor de assuntos menos técnicos, como Administração.

No entanto, a experiência da Open University do Reino Unido e de outras provedoras de educação a distância mostra claramente que a tecnologia e o ensino da engenharia podem ser muito bem sucedidos na entrega a distância.

Deve-se separar e promover o nome de escolas que levam a sério a qualidade da educação a distância e não generalizar com discursos de repúdio à EaD. 


\section{RECURSOS USADOS NA EDUCAÇÃO A DISTÂNCIA}

Um conceito importante a entender é a diferença entre duas formas distintas de comunicação: síncrona e assíncrona.

Comunicação síncrona é a comunicação na qual todas as partes participam ao mesmo tempo. A comunicação síncrona na educação a distância enfatiza uma experiência de aprendizado em grupo simultânea. Professores e alunos se comunicam em tempo real.

Comunicação assíncrona é a comunicação na qual as partes participam em momentos diferentes. A comunicação assíncrona oferece uma escolha de onde e, acima de tudo, quando o aluno acessará o aprendizado, podendo ler ou visualizar esses materiais conforme sua conveniência.

A maioria dos professores e alunos está muito mais familiarizada com a comunicação síncrona na educação. À medida que as TIC se desenvolvem, os professores de educação a distância as experimentam para encontrar maneiras de melhorar as interações professor-aluno e aluno-aluno, sejam elas síncronas ou assíncronas, sem se descuidar dos aspectos relacionados às demandas psicopedagógicas, adequadas ao perfil cognitivo do aluno on-line.

Atualmente, os cursos de engenharia considerados de qualidade utilizam os seguintes recursos:

- Polos de apoio presencial;

- Videoaulas correspondentes à carga horária do curso;

- Materiais em múltiplas mídias;

- Oficinas de fim de semana;

- Kits experimentais práticos domésticos;

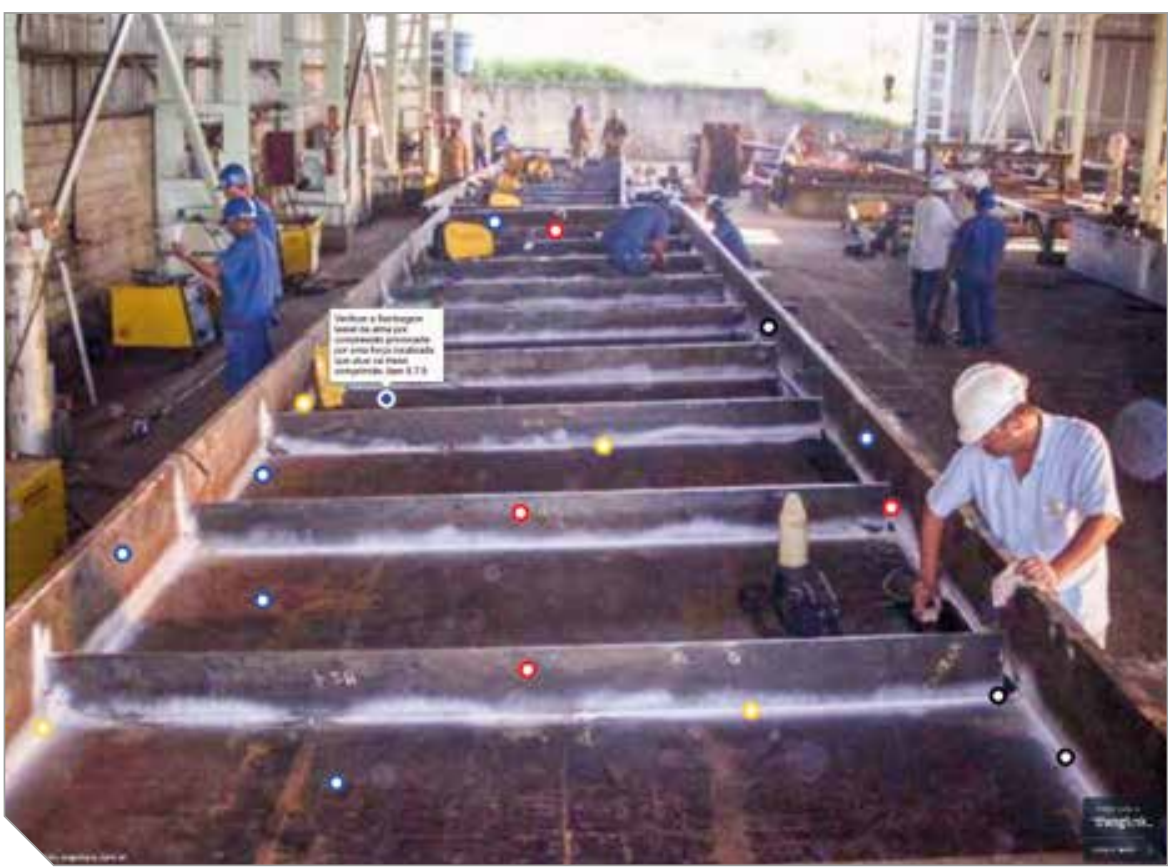

Infográfico interativo com tags adotado na GaD para o aluno explorar conteúdo adicional

> Organização ou laboratórios móveis disponibilizados nos polos de apoio presencial, atuando como um centro prático para acesso do aluno;

- Programas projetados para atender às necessidades do estágio e que incorporam treinamento prático nas empresas, no local de trabalho;

> Web conferências semanais entre professores e alunos;

- Assinaturas de bibliotecas virtuais e provedores de normas digitais, para disponibilização de títulos on-line:

- Oferta de programas de monitoria e iniciação científica a distância;

> Fóruns de discussão entre alunos, tutores, professores e coordenadores. Outras opções incluem:

- Vídeos como substitutos para trabalhos de laboratório;

> O uso de simuladores e weblab (laboratórios por acesso remoto). É amplamente aceito que a EaD terá um papel cada vez mais importante a desempenhar na educação e na formação, assim novas tecnologias, sem dúvida, terão profunda influência na educação no futuro.

\section{EVOLUÇÃO DAS TIC NOS PROJETOS DE EDUCAÇÃO A DISTÂNCIA}

A EaD é uma estratégia que vem sendo a propulsora de cursos em IES, mas também do surgimento de significativa quantidade de cursos de formação continuada, cursos livres de atualização profissional, sendo sua evolução correlacionada com a evolução das TIC.

No futuro, o poder de processamento de computadores deve continuar a aumentar na mesma grande taxa que nas décadas de 1980 e 1990. A internet 2.0, uma internet de alta velocidade focada em educação e pesquisa, é uma das muitas opções de comunicação de alta velocidade que estão em desenvolvimento.

O serviço de televisão digital, vídeo, áudio, texto e gráficos, com 


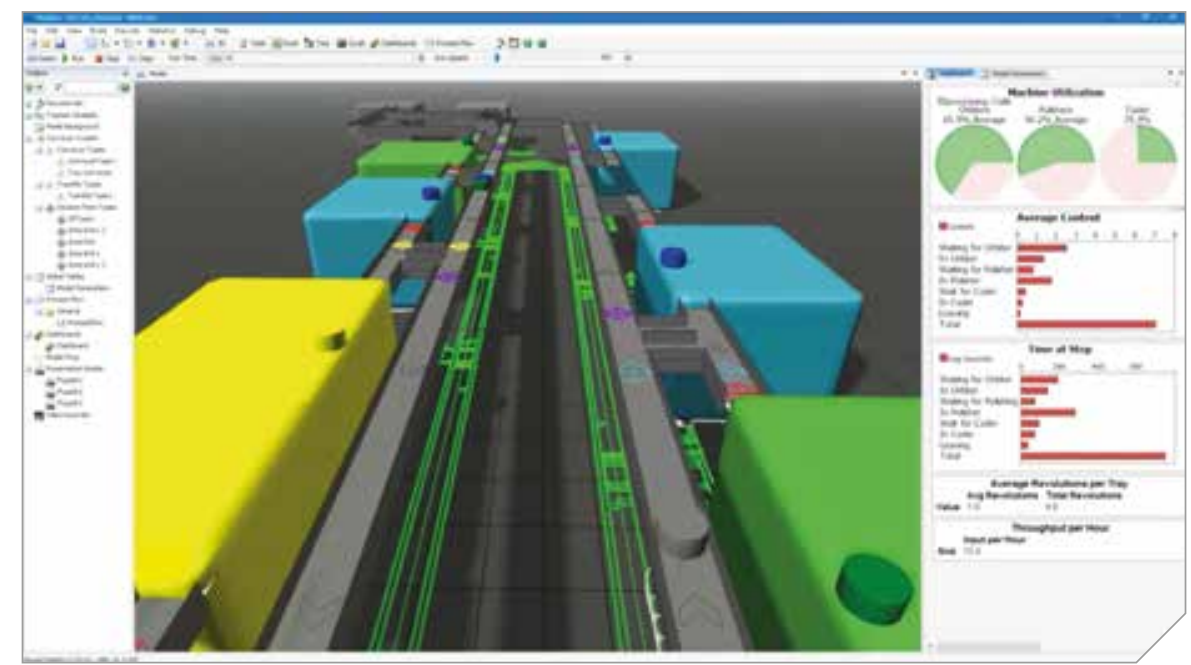

Exemplos de simuladores usados na EaD do curso de Engenharia de Produção da Universidade Virtual do Estado de São Paulo (UNIVESP)

interatividade, entregue pela rede IP (Internet Protocol), denominada IPTV, utilizando banda larga com grande capacidade de transmissão e canal de retorno, tende a ser adotada pela EaD, pois "possui as características de uma mídia completa para ser usada na Educação a Distância, principalmente no Ensino de Engenharia" (AZAMBUJA et al. , 2020).

Novas tecnologias interativas aumentarão a sensação de presença e imersão: Realidade Aumentada (RA), Realidade Virtual (RV), integrações entre disciplinas utilizando o Building Information Modeling (BIM), a Inteligência Artificial, aplicativos de videoconferência e programas compartilhados.

Com óculos de realidade virtual, os alunos poderão entrar numa Usina Hidrelétrica e estudar a estrutura da barragem virtual, toda em 3D. Poderão viajar por dentro das tubulações, isolar seus sistemas, optando por ver só o sistema hidráulico, ou o elétrico, pegar as turbinas e obter todas as informações técnicas sobre elas, colocar em funcionamento, medir pressão, fluxo, tensões e deslocamentos na estrutura de concreto da barra- gem, ou simular manifestações patológicas e acidentes. Depois, os alunos podem fazer um teste na plataforma para verificar o que aprenderam.

Outro aspecto muito discutido é a simulação da Realidade Aumentada que proporciona uma integração perfeita com o aluno, sem necessidade de treinamento, a partir da utilização de objetos virtuais, aumentando a visão do mundo real. As técnicas de computação gráfica permitem a sobreposição de objetos virtuais com a imagem real. Além de permitir que objetos virtuais possam ser introduzidos em ambientes reais, a Realidade Aumentada proporciona também, ao usuário, o manuseio desses objetos com as próprias mãos, possibilitando uma interação atrativa e motivadora com o ambiente. A adaptação dos softwares é incrivelmente facilitada.

O fator primordial no ensino de qualquer curso de engenharia é a utilização de laboratórios, que, por exigência dos órgãos da Educação, devem ser presenciais. Entretanto, com os avanços tecnológicos, tem-se todas as condições de transformar laboratórios presenciais em laboratórios virtuais.
No estudo das Engenharias, laboratórios virtuais nas diversas áreas possibilitariam aos estudantes comprovações técnicas dos estudos teóricos, mas de forma mais continuada e acessível.

Verifica-se, sem controvérsia, a importância dos laboratórios virtuais nos cursos de Engenharia Aeronáutica, com os simuladores de voo, assim como na Engenharia Aeroespacial e na Engenharia Nuclear. Desta forma, a mesma importância poderia ser dada aos laboratórios voltados às áreas de Civil, Mecânica, Produção, Mecatrônica, Química, Eletrônica e Elétrica, possibilitando aos estudantes uma proximidade dos conceitos à prática.

Esses avanços permitirão que os alunos a distância tenham mais acesso às simulações síncronas e assíncronas de áudio, vídeo e computador.

Observar como a tecnologia pode contribuir com a construção do conhecimento possibilita desenvolver ferramentas computacionais que apresentam resultados ótimos no processo. Elas permitem: 1) estabelecer os conceitos estruturantes, com aproveitamento máximo da capacidade cognitiva do aluno; 2) desenvolver softwares altamente interativos que permitem vencer as limitações impostas pelos laboratórios presenciais, acrescentando possibilidades nunca imaginadas nesses aspectos.

Um curso de engenharia EaD será bem-sucedido e reconhecido pela sociedade, se houver a atuação de especialistas no assunto e profissionais da área da instrução que organizem o conteúdo, de acordo com a teoria e a prática da gestão da informação e das teorias da aprendizagem, e uma percepção da aplicação de boas práticas, tais como: 
- Uso da mesma matriz curricular e carga horária na modalidade EaD e na modalidade presencial;

- Análise cuidadosa das necessidades dos alunos e funcionários antes do desenvolvimento de um curso;

- Esboço claro dos objetivos, competências e aprendizado específicos;

- Objetivos a serem obtidos com o curso;

- Produção de materiais didáticos de alta qualidade, projetados para serem fáceis de usar, escritos por especialistas e testados pelo consumidor;

- Uso de mídia apropriada para cada conteúdo apresentado;

> Fornecimento de um ensino remoto dedicado e de boa qualidade;

- Administração que responda prontamente aos alunos e forneça apoio local em polos;

> Sistema eficiente de backup, monitoramento, tutoria e avaliação regulares;

- Preocupação pessoal customizada com os alunos: mantendo contato e verificando seu progresso, possivelmente utilizando inteligência artificial;

- Instruções claras em relação à avaliação e ao progresso do aluno, construtiva e rápida, com feedback contínuo;

- Tutores on-line comprometidos e bem qualificados, bem treinados em técnicas de educação a distância;

- Tutoria local nos polos de apoio e suporte prático;

- Encontros presenciais regulares para práticas de laboratório, projetos integradores e avaliações nos polos de apoio;

- Definição clara das diretrizes para estudantes sobre as habilidades e autonomia necessárias de estudo;

- Flexibilidade do tempo de estudo e oportunidades para alterar o ritmo de estudo.

\section{RESPOSTA DA EAD À PANDEMIA DE COVID-I9}

A COVID-19 resultou em escolas fechadas ao redor do mundo. Como resultado, a educação mudou drasticamente, com a transformação repentina de cursos presenciais em cursos a distância.

Com essa mudança da sala de aula, alguns estão se perguntando se a adoção da EaD continuará após a pandemia e como essa mudança afetará o mercado educacional mundial.

Conforme citado anteriormente, mesmo antes da COVID-19, já havia um alto crescimento e adoção em tecnologia educacional, com investimentos globais, seja em aplicativos de idiomas, aulas virtuais, ferramentas de videoconferência ou softwares de aprendizado on-line, mas, em curtíssimo espaço de tempo, houve um aumento significativo de investimento e no uso desde a decretação da pandemia.

Por exemplo, a startup americana Zoom Video, dona do aplicativo de videoconferências mais popular do momento, já supera em valor de mercado, a Vale, a Petrobras, a Ambev e o Itaú Unibanco (EXAME, 2020).

O que isso significa para o futuro da aprendizagem?

Enquanto alguns acreditam que a mudança rápida e não planejada para o aprendizado on-line, sem treinamento, com largura de banda insuficiente e pouca preparação, resultará em uma má experiência do usuário, que não conduzirá ao crescimento sustentado, outros acreditam que um novo modelo híbrido de educação surgirá, com benefícios significativos.

Tudo indica que a integração da tecnologia da informação na educação será acelerada a partir de agora e que a educação remota acabará se tornando um componente integral da educação universitária.

Já houve transições bem-sucedidas nas universidades. Por exemplo, a UFSCar utilizou a plataforma Engeduca para não paralisar o curso de pós-graduação presencial Gestão e Tecnologia de Sistemas Construtivos de Edificações. A UNISA adaptou todos os seus cursos presenciais de engenharia para a forma remota em apenas uma semana, usando o aplicativo Teams da Microsoft.

Muitos professores que nunca atuaram na $\mathrm{EaD}$ já estão percebendo os benefícios, pois muda a maneira de ensinar. Os recursos disponíveis permitem alcançar os alunos de maneira mais eficiente e eficaz, por meio de grupos de bate-papo, videoconferências, votação e compartilhamento de documentos, especialmente durante esta pandemia. Depois do coronavírus, acredito que o aprendizado off-line tradicional e o on-line estarão de mãos dadas.

Entretanto, não há dúvidas, a falta de planejamento gerou problemas. Alguns estudantes sem acesso confiável à Internet e / ou tecnologia lutam para participar do aprendizado digital; essa diferença é observada entre as diferentes faixas de renda.

É claro que essa pandemia interrompeu totalmente o sistema educacional tradicional, mas em seu 
livro, 21 Lições para o século XXI, Yuval Noah Harari (2018) descreve como as escolas continuam a se concentrar nas habilidades acadêmicas tradicionais e na aprendizagem mecânica, em vez de habilidades como pensamento crítico e adaptabilidade, que serão mais importantes para o sucesso no futuro. A mudança para o aprendizado on-line poderia ser o catalisador para criar um método novo e mais eficaz de educar os alunos. Enquanto alguns temem que a natureza apressada da transição on-line possa ter prejudicado esse objetivo, outros planejam tornar a EaD parte de seu 'novo normal' depois de experimentar os benefícios em primeira mão.

O que ficou claro com essa pandemia é a importância da disseminação do conhecimento entre fronteiras, empresas e todas as partes da sociedade. Se a tecnologia de aprendizado on-line pode desempenhar um papel aqui, cabe a todos nós explorar todo o seu potencial.

\section{COMENTÁRIOS FINAIS}

É preciso compreender que a Educação a Distância confia na atitude, na responsabilidade e na autonomia de cada aluno, além de requerer forte compromisso institucional para garantir o processo de formação.

Não se chegou lá ainda, mas esse é um caminho sem volta: alunos autônomos e professores como gestores do conhecimento, pois é muito mais rico ensinar a pensar, ao invés de decorar.

Tradicionalmente, muitos sistemas de ensino falam sobre uma resposta certa. O professor faz uma pergunta ao aluno e espera uma resposta. No final do ano, ele aplica uma prova e o aluno precisa escrever a resposta certa. Isso não é mais importante para o século XXI.

É uma ideia muito ruim ensinar engenharia dizendo que existe apenas uma resposta certa. A real prova que o professor deve aplicar, ao fim do ano, deve ter questões que o aluno nunca teve acesso antes, para ver como ele lida com uma informação nova, com algo que ele nunca viu. Essa reflexão é o único ensinamento que ele precisa. A EaD contribui sobremaneira com essa visão.

A educação a distância está tão sujeito às forças do mercado quanto qualquer outro produto ou serviço. Provedores precisam ter em mente que as noções de valor agregado e atendimento ao cliente se aplicam neste campo como em qualquer outro e o provedor precisará, portanto, usar toda uma gama de estratégias para manter essa pessoa satisfeita e motivada para manter a sua matrícula.

O mercado os selecionará com base nas boas práticas e sistemas de qualidade.

Há desafios a serem superados, mas a EaD já tornou-se uma parte necessária do sistema educacional.

O preconceito só dificultará superar esses desafios.

\section{REFERÊNCIAS BIBLIOGRÁFICAS}

[01] ABMES. Ainda há preconceito no mercado de trabalho com quem faz ead? 2018. Disponível em: <https://abmes.org.br/noticias/detalhe/2980/ainda-hapreconceito-no-mercado-de-trabalho-com-quem-faz-ead->. Acesso em: 03 maio 2020.

[02] AECT. Distanceeducation. Disponivel em: <http://members.aect.org/edtech/ed1/13/13-02.html>.Acesso em 18 abr, 2020.

[03] AZAMBUJA, MARCOS JOLBERT CÁCERES; GRIMONI, JOSÉ AQUILES BAESSO; CURY, LUCILENE. Tecnologias digitais para a educação em engenharia: iptv na EAD - conceitos e propostas. In COBENGE, 2014, Juiz de Fora. Anais... Juiz de Fora, MG. Disponivel em: <http://www3.eca.usp.br/sites/default/files/form/biblioteca/ acervo/producao-academica/002658292.pdf $>$. Acesso em: 03 maio 2020.

[04] CORRÊA, S. de C. \& SANTOS, L. M. M. dos. Preconceito e educação a distância: atitudes de estudantes universitários sobre os cursos de graduação na modalidade a distância. 2009. ETD - EducaçãoTemática Digital, 11(1), 273-297.

[05] E-LEARNING INDUSTRY, The History Of Distance Learning - Infographic. Disponivel em:<https://elearningindustry.com/the-history-of-distance-learninginfographic >. Acesso em: 02 maio 2020.

[06] EXAME. Zoom decola com coronavírus e já vale mais que Vale, Petrobras e Ambev. Publicado em 20.05.2020. Disponível em: <https://exame.com/mercados/ zoom-decola-com-coronavirus-e-ja-vale-mais-que-vale-petrobras-e-ambev/>. Acesso em 21 maio 2020.

[07] Harari, Yuval Noah.21 lições para o século 21; tradução Paulo Geiger. — 1a ed. — São Paulo: Companhia das Letras, 2018.

[08] INEP.Sinopses Estatísticas da Educação Superior - Graduação. Disponível em:<http://inep.gov.br/web/guest/sinopses-estatisticas-da-educacao-superior>. Acesso em: 02 maio 2020.

[09] MEC. Educação superior a distância. Disponível em: <http://portal.mec.gov.br/instituicoes-credenciadas/educacao-superior-a-distancia> Acesso em 18 abr. 2020.

[10] MEC. Referenciais de qualidade para educação superior a distância. Disponivel em: <http://portal.mec.gov.br/seed/arquivos/pdf/legislacao/refead1.pdf>. Acesso em 02maio 2020.

[11] OPEN UNIVERSITY.One of Wilson's greatest achievements. Disponivel em: <https://www.open.ac.uk/library/digital-archive/exhibition/74/theme/4/page/1> Acesso em 02 maio 2020. 